\title{
С.А. Власов*
}

\author{
РЕФОРМА ЖИЛИЩНО-КОММУНАЛЬНОГО ХОЗЯЙСТВА \\ В МАЛЫХ И СРЕДНИХ ГОРОДАХ \\ ДАЛЬНЕВОСТОЧНОГО ФЕДЕРАЛЬНОГО ОКРУГА (1992-2017 гг.)
}

\begin{abstract}
В статье дан анализ реформы жилищно-коммунального хозяйства в малых и средних городах Дальневосточного федерального округа; выявлено, что переход отрасли на самофинансирование и самоокупаемость не был достигнут из-за низкой платежеспособности населения. Основные мероприятия реформы, связанные с значительными финансовыми затратами, - модернизация инженерной инфраструктуры, переселение граждан из аварийного и ветхого жилья - проводились благодаря финансированию из федерального и регионального бюджетов. Автором сформулированы рекомендации по оказанию дальнейшей помощи муниципалитетам малых и средних городов с учетом социально-экономической ситуации в каждом конкретном городе.
\end{abstract}

Ключевые слова: жилищно-коммунальное хозяйство, реформа, субсидии, модернизация инфраструктуры, аварийное жилье, капитальный ремонт

The reform of housing and communal services in small and medium-sized towns of the Far Eastern Federal District, 1992-2017. SERGEY A. VLASOV (Institute of History, Archaeology and Ethnography of the Peoples of the Far East, Far Eastern Branch of Russian Academy of Sciences)

The article analyzes the reform of housing and communal services in small and medium-sized towns of the Far Eastern Federal District. The research reveals that the industry's transition to self-financing and self-sufficiency was not achieved due to the low paying capacity of residential consumers. The main reform measures requiring significant expenditures (the modernization of engineering infrastructure, relocation from emergency housing, etc.) were carried out thanks to funding from the federal and regional budgets. The author formulates recommendations for further assistance to municipalities of small and medium-sized towns, taking into account the socio-economic situation in each specific case.

Keywords: housing and communal services, subsidies, infrastructure modernization, emergency housing, major repairs

В истории, экономике, географии, градостроительстве и других науках при подразделении городов на малые, средние, большие и крупные главным детерминирующим критерием является численность населения. В соответствии с градостроительными нормами от 02.07.1989 г. к группе малых городов относятся поселения с численностью до 50 тыс. чел., к средним - от 50 до 100 тыс.

\footnotetext{
* ВЛАСОВ Сергей Александрович, кандидат исторических наук, старший научный сотрудник отдела истории Дальнего Востока России Института истории, археологии и этнографии народов Дальнего Востока Дальневосточного отделения РАН.

E-mail: vlasov54@bk.ru

(C) Власов С.А., 2019
} 
В Дальневосточном федеральном округе (ДФО) на 1 января 2017 г. 64 поселения имели статут города, из них 54 относились к малым и средним. Во всех городах ДФО проживало 4,679 млн. чел., в том числе в больших и крупных 2,809 млн., в малых и средних - 1,870 млн. чел., что составляло 66,5\% городских жителей ДФО или $30,2 \%$ всего населения ДФО ${ }^{1}$, которое насчитывало 6,183 млн. чел.

Таким образом, учитывая, что в малых и средних городах ДФО сосредоточена значительная часть населения региона, представляется, что исследование проблемы реформирования жилищно-коммунального хозяйства в них является актуальной. Из этого вытекает цель данной статьи - показать, как проводилась реформа жилищно-коммунального хозяйства (ЖКХ) в малых и средних городах ДФО.

Для достижения поставленной цели потребовалось выяснить, насколько успешно был осуществлен переход ЖКХ на самофинансирование и самоокупаемость в малых и средних городах; как осуществлялась модернизация инженерной инфраструктуры ЖКХ; как решалась проблема ликвидации аварийного и ветхого жилья в регионе; насколько успешно проводилось реформирование ЖКХ, учитывая различие в социально-экономической ситуации малых и средних городов; каким образом и в каких объемах осуществлялась помощь из федерального бюджета малым и средним городам ДФО.

Основным отличием социально-экономической жизни малых и средних городов от крупных является зависимость от одного-двух градообразующих предприятий, на которых трудится большая часть горожан.

В начале 1990-х гг, когда в нашей стране начались радикальные экономические реформы, практически все малые и средние города в ДФО оказались в крайне сложном положении. Позитивные тенденции в их развитии, отмечавшиеся ранее, в 1960-е - 1980-е гг., оказались деформированы, а в отдельных случаях просто сошли на нет, что было связано с адаптацией перехода к рынку и спонтанной реструктуризацией экономики. В этой тяжелой ситуации, когда многие горожане оказались без работы и средств к существованию, началась реформа жилищно-коммунального хозяйства.

Главная цель реформы ЖКХ заключалась в переводе отрасли на самофинансирование и самоокупаемость, полном отказе от государствен-

${ }^{1}$ Подсчитано автором на основании источников: $[13$, с. $664 ; 18$, с. $86,92-94]$. ных дотаций и бюджетного финансирования. Поначалу предполагалось, что через пять лет после того, как был принят Федеральный закон «Об основах федеральной жилищной политики» (24 декабря 1992 г.), к 1998 г. население будет полностью оплачивать жилищно-коммунальные услуги. Столь короткий срок был выбран исходя из того, что реформаторы предполагали быстрый экономический рост в стране и регионах, рассчитывая на переход к рыночным отношениям. Но этого не произошло. Напротив, реальные доходы граждан РФ существенно снизились, при этом тарифы на жилищно-коммунальные услуги (ЖКУ) резко возросли.

Неспособность населения полностью оплачивать ЖКУ побудила федеральные и региональные органы власти принять меры по оказанию помощи (в виде субсидий) гражданам, имеющим низкие доходы. Согласно Федеральному законодательству, субсидии получали те граждане, у которых доля расходов на оплату жилого помещения и коммунальных услуг в совокупном доходе семьи превышала размеры в пределах от 15 до $22 \%$. Конкретную величину устанавливали сами субъекты Российской Федерации. В ДФО минимальный порог (15\%) был в Якутии и Еврейской автономной области (ЕАО), максимальный $(22 \%)$ - в Приморском и Хабаровском краях.

С сентября 1998 г. Госкомстат России стал учитывать число семей, получающих субсидии на оплату ЖКУ, и ее размеры. По ДФО мы располагаем статистическими данными с 2000 по 2016 гг., что позволяет проследить динамику роста числа семей, получающих субсидии, и выяснить, насколько успешно решалась одна из задач, поставленных в ходе реформы ЖКХ, переход отрасли на самофинансирование и самоокупаемость (см. табл. 1).

Данные таблица свидетельствуют о значительной доле семей в ДФО, получающих субсидии, в сравнении со среднероссийскими показателями. Здесь важно отметить, что в ДФО основными получателями такой помощи были жители малых и средних городов, так как многие из них, лишившись постоянной работы, были вынуждены жить за счет случайных заработков, которых едва хватало на самое необходимое - еду и одежду.

Субсидии сделали услуги ЖКХ доступнее для части потребителей и помогли им справиться с ростом тарифов, однако они не позволили отрасли перейти на самоокупаемость, поскольку параллельно сохранялась проблема своевременной оплаты услуг другими потребителями. 
Предоставление гражданам субсидий на оплату жилищно-коммунальных услуг в Российской Федерации и ДФО в 2000-2016 гг.

\begin{tabular}{|l|c|c|c|c|c|}
\hline & $\mathbf{2 0 0 0}$ г. & $\mathbf{2 0 0 5}$ г. & $\mathbf{2 0 1 0}$ г. & $\mathbf{2 0 1 3}$ г. & $\mathbf{2 0 1 6}$ г. \\
\hline Число семей, получающих субсидии в РФ, \% & 7,7 & 11,9 & 7,3 & 6,4 & 6,0 \\
\hline Средний размер субсидии, руб. & 80 & 550 & 896 & 1096 & 1372 \\
\hline Число семей, получающих субсидии в ДФО, \% & 11,4 & 17,2 & 10,4 & 8,5 & 7,3 \\
\hline Средний размер субсидии, руб. & 170 & 853 & 1528 & 1715 & 1868 \\
\hline
\end{tabular}

Источники: [14, с. 170, 171, 177-178; 17, с. 330-333].

Задолженность потребителей, появившаяся в 1990-е гг., в начале реформы ЖКХ, стала обыденным явлением. Долги потребителей ЖКУ росли из года в год. Из общей суммы задолженности сложно выделить долги жителей малых и средних городов, такая статистика не ведется. Мы можем пользоваться лишь отрывочными данными, полученными из средств массовой информации и Интернета, но и они достаточно красноречивы. Так, в 2004 г. долг жителей г. Свободный (63 тыс. чел.) Амурской области за потребленные жилищно-коммунальные услуги достиг суммы, превышающей 50 млн. руб. [7]. По состоянию на 1 июня 2013 г. население Биробиджана $(75,5$ тыс. чел.) в ЕАО задолжало за ЖКУ 409 млн. руб. [10]. На начало августа 2015 г. задолженность населения г. Зея (24 тыс. чел.) Амурской области за ЖКУ составила 69,4 млн. руб. [4].

Несвоевременная оплата ЖКУ породила проблему нехватки средств, результатом чего стала практика, когда планово-предупредительный ремонт объектов ЖКХ полностью уступил место аварийно-восстановительным работам. Инженерная инфраструктура стареет, ветшает, приходит в негодность. Неприемлемо высокий уровень физического и морального износа инженерной инфраструктуры приводит к значительным непроизводственным потерям теплоэнергии, воды и других видов ресурсов, которые покрываются за счет повышения тарифов на ЖКУ. Таким образом, складывается замкнутый круг, когда неплатежи потребителей не позволяют модернизировать инфраструктуру, а уста- ревшая инфраструктура побуждает повышать тарифы.

Неплатежи приводят к тому, что у предприятий ЖКХ нет средств на модернизацию инженерной инфраструктуры. По итогам отопительного сезона 2012-2013 гг. в ДФО было зафиксировано 456 аварий, большинство из которых произошли в Республике Саха (Якутия) и Хабаровском крае (161 и 155 соответственно). Основной причиной стала ветхость сетевой инфраструктуры. В коммунальном хозяйстве ДФО ветхими призваны 20\% электрических, $33 \%$ тепловых, $45 \%$ водопроводных и $46 \%$ канализационных сетей [5]. На плановую их замену (ежегодно должно обновляться не менее 6\%) необходимо направлять до 11 млрд. руб. в год, но такую сумму получить только с потребителей невозможно. Здесь необходимо решать проблему комплексно - за счет населения, бюджета, частных инвестиций.

Реальность такова, что инженерная инфраструктура в малых и средних городах модернизируется в основном за бюджетные средства: частным инвесторам в силу низких доходов населения и ограниченности рынка вкладывать средства в эту сферу невыгодно.

В 2002 г. в Амурской области была принята областная программа «Реформирование и модернизация жилищно-коммунального комплекса Амурской области на 2003-2010 гг.». В рамках программы на эти цели было выделено 322 млн. руб. из областного бюджета и 100 млн. из муниципальных бюджетов городов и районов области [3]. За счет бюджетных средств 
удалось модернизировать котельную в Белогорске, выполнить ряд других работ. Но существенно улучшить ситуацию с реконструкцией и заменой обветшалого, устаревшего оборудования не удалось, поэтому начиная с 2010 г. правительством области принимались новые программы. В настоящее время в области действует программа, вступившая в силу с 1 января 2014 г. и рассчитанная до 2020 г. В рамках этой программы продолжается работа по модернизации инфраструктуры ЖКХ малых и средних городов. В частности, предстоит реконструировать водопроводные и канализационные сети в городах Белогорск, Зея, Райчихинск, Свободный, где неочищенные стоки сбрасываются в водоемы бассейна Амура.

Еще одним фактором, побуждающим тратить бюджетные деньги на модернизацию жилищно-коммунального комплекса малых и средних городов, является то, что в 2012 г. Министерством обороны РФ было принято решение о передаче бывших военных городков со всеми коммуникациями и земельными участками в ведение местных муниципалитетов. Большинство таких поселений находится в границах малых и средних городов. Так, муниципалитету Дальнереченска (Приморский край) по приказу Министерства обороны было передано четыре военных городка, в которых жилые дома, сетевая инфраструктура, котельные, насосные и прочие объекты длительное время капитально не ремонтировались. У муниципалитета нет средств, чтобы все это отремонтировать и модернизировать. Подобная ситуация складывается и в других городах Приморского края - Спасске-Дальнем и Лесозаводске. По оценке администрации Приморского края, в связи с передачей военных городков местным муниципалитетам необходима помощь из федерального бюджета в размере не менее 2 млрд. руб. для приведения в порядок инженерно-коммунальной инфраструктуры [11].

Нехватка финансов, невозможность покрывать расходы ЖКХ за счет потребителей породили еще одну проблему - быстрый рост ветхого и аварийного жилья. Изменения в социально-экономическом развитии России в 1990-е гг. привели к значительному снижению инвестиций в жилищно-коммунальную сферу, средства на капитальный ремонт жилого фонда не выделялись, к тому же резко упали объемы жилищного строительства - все это ускорило темпы старения и выбытия существующего жи- лья. Долгое время проблеме ликвидации ветхого и аварийного жилья не уделялось должного внимания, средств для ее решения выделялось мало. Так, в 2004 г. из федерального бюджета на все субъекты выделили всего 300 млн. руб., а в последующие два года сумма немного возросла и составила по 1 млрд. руб. за год [9]. В ДФО средств выделялось также крайне мало.

Ситуация изменилась после того, как в июле 2007 г. был принят Федеральный закон «О фонде содействия реформирования жилищно-коммунального хозяйства». Фонд создавался как некоммерческая организация, осуществляющая функции по предоставлению финансовой поддержки субъектам Российской Федерации и муниципальным образованиям на капитальный ремонт многоквартирных домов (МКД) и переселение граждан из аварийного жилья. С 2008 г. благодаря созданному Фонду началась реальная работа по решению этой проблемы. К этому времени удельный вес ветхого и аварийного жилья в общем жилищном фонде ДФО составлял $6,2 \%$, почти в два раза больше, чем в Российской Федерации (3,2\%) [16, с. 270-273]. Больше всего ветхого и аварийного жилья было в Якутии (15,6\%), Магаданской (11,3\%), Сахалинской $(9,7 \%)$ и Амурской $(8,5 \%)$ областях [15, c. 216-217], причем в малых и средних городах. Так, в Тынде (Амурская область) по данным на 2008 г. 7 тыс. чел. (то есть почти каждый шестой житель города) жили во времянках, щитовых и сборных домиках, вагончиках времен строительства Байкало-Амурской магистрали. Много ветхого и аварийного жилья было и в других малых и средних города Амурской области Белогорске, Райчихинске, Свободном. Ликвидация подобного жилья, строительство нового и расселение граждан - все это началось лишь после того, как был создан Фонд содействия реформированию ЖКХ. Благодаря финансированию из Фонда проблема аварийного жилья стала активно решаться не только в Тынде, но и других малых и средних города области - Белогорске, Райчихинске, Свободном. В последнем работа по ликвидации ветхого и аварийного жилья проводилась особенно активно. В рамках программы по расселению граждан из аварийного жилищного фонда, признанного таковым по состоянию на 1 января 2012 г., в Свободном только за один 2014 г. сдали в эксплуатацию несколько жилых домов общей площадью 10 тыс. кв. м, 600 чел. переехали из бараков в благоустроенные квартиры [2]. Всего за время дей- 
ствия программы здесь расселено более 40 тыс. кв. м аварийного жилья, новые квартиры получили более 2 тыс. граждан [6]. Тем не менее, к 1 сентября 2017 г. в Свободном не удалось полностью завершить программу по переселению граждан из аварийного жилищного фонда, призванного таковым по состоянию на 1 января 2012 г., как и в других городах Амурской области - Белогорске, Райчихинске и Шимановске. Основной причиной срыва сроков реализации программы явилось отсутствие средств в областном бюджете, необходимых для долевого софинансирования программных мероприятий.

В ДФО, помимо Амурской области, выполнить программу по расселению граждан из домов, призванных аварийными, в срок (к 1 сентября 2017 г.) не успели еще три региона: Якутия, Приморский край и Еврейская автономная область.

Устранение в ближайшей перспективе аварийного и сокращение объемов ветхого жилья невозможно без организации системы капитального ремонта многоквартирных домов. Капитальный ремонт является крайне важным для сохранности жилого фонда, поскольку здания постепенно стареют, ветшают, чтобы сдержать этот процесс необходимо регулярно ремонтировать жилые помещения. Здесь, как и в модернизации инфраструктуры ЖКХ, ключевой проблемой является обеспечение капремонта финансовыми ресурсами. Решать ее только за счет федерального и регионального бюджета невозможно, необходимо участие населения.

С 2014 г. все собственники жилых помещений в многоквартирных домах ДФО стали платить взносы на капитальный ремонт. В региональные программы по капитальному ремонту общего имущества в многоквартирных домах, расположенных на территории ДФО, вошли МКД, кроме призванных ветхими и аварийными.

Введение дополнительной платы за капитальный ремонт разделило собственников жилых помещений в ДФО на два лагеря: одни стали исправно платить за будущий ремонт своего дома, другие не поверили, что их жилье приведут в порядок через несколько лет, когда до их дома дойдет очередь. Как результат - часть жителей округа проигнорировали оплату взносов в региональный Фонд капитального ремонта, который собирает деньги, а затем выдает их для ремонта. Среди тех, кто отказывался платить, велика доля жителей малых и средних городов. У кого-то просто нет средств на допол- нительный платеж, другие считают, что схема с региональным фондом похожа на финансовую пирамиду, в выигрыше останутся жильцы домов-первоочередников, остальным денег не хватит или их «съест» инфляция.

Собираемость взносов на капремонт наглядно проявила разную социально-экономическую ситуацию в малых и средних городах. В одних, таких как Циолковский и Свободный в Амурской области, Большой Камень в Приморском крае, имеются прекрасные перспективы для развития, в них реализуются важные федеральные программы и проекты. Жители этих городов имеют работу, у них неплохие заработки и есть основания для оптимизма и долгосрочных жизненных планов. В Циолковском продолжаются работы на космодроме «Восточный», где весной 2016 г. состоялся первый запуск ракеты-носителя с тремя спутниками. В дальнейшем там планируется запуск пилотируемых космических ракет с космонавтами на борту. В Свободном работает старейшее предприятие города - вагоноремонтный завод, кроме того, по распоряжению Правительства Российской Федерации создана территория опережающего развития (ТОР), ведется строительство газоперерабатывающего завода, где будут трудиться 5 тыс. чел. В Большом Камне ведутся работы по созданию крупной судостроительной верфи, где будут строиться крупнотоннажные морские суда.

Другие города - Тында, Зея (Амурская область), Арсеньев (Приморский край) - также находятся в сравнительно неплохой ситуации, градообразующие предприятий (железная дорога, гидроэлектростанция, промышленные предприятия) работают стабильно. Но у большинства городов ДФО, прежде всего малых, перспективы туманны. Отсутствие стабильно работающих предприятий, низкий уровень доходов горожан, отток молодежи, старение населения и другие негативные тенденции - все это создает неблагоприятный фон для жителей, которые находятся в депрессивном состоянии и не строят планы на будущее. Очевидно, что сложная социально-экономическая ситуация в таких депрессивных городах затрудняет проведение реформы ЖКХ.

Практика показала, что наиболее благоприятные тенденции развития жилищно-коммунального комплекса (ЖКК) наблюдаются в городах с высокой численностью населения, что создает условия для рынка ЖКУ. Здесь 
также сказывается плотность населения и жилого фонда, площадь многоквартирных домов. Численность населения формирует количество потребителей жилищно-коммунальных услуг, а плотность населения, жилого фонда и протяженность инженерных коммуникаций являются факторами для эффективной работы ЖКК. Если жилые дома расположены компактно и в городе проживает достаточно много населения, то затраты на содержание и эксплуатацию инженерных сетей распределяются на большое число потребителей. Следовательно, у предприятий ЖКХ уходит меньше средств на содержание инфраструктуры и остаются деньги на получение дополнительной прибыли.

В малых и средних городах жилой фонд составляют малоэтажные жилые постройки (не более 5 этажей) и индивидуальные отдельно стоящие жилые дома, рассредоточенные на значительной площади. Следовательно, затраты на эксплуатацию, текущее содержание и капитальный ремонт инженерных сетей распределяются на меньшее количество потребителей коммунальных услуг. Поэтому данные затраты в расчете на одного потребителя в малых и средних городах существенно превышают аналогичные затраты в большом городе.

Так, в Свободном (Амурская область) ООО «Аква» является основным поставщиков услуг по водоснабжению и водоотведению в городе. На балансе предприятия находится 71 км водопроводных сетей, 45 км канализационных. Большой километраж коммуникаций приходится на небольшую численность населения города. Протяженность водопровода на 100 квартир в Свободном намного больше, чем в областном центре - Благовещенске, численность населения которого составляет 224,3 тыс. чел. и превышает численность населения Свободного в четыре с лишним раза. Предприятию ООО «Аква» трудно проводить модернизацию инженерных сетей, изношенность которых достигла $60 \%$. Полностью решить проблему за счет потребителей, повышая тариф, нет возможности, так как при существующих расценках горожане задолжали предприятию 15 млн. руб. [8].

Как правило, ресурсоснабжающие предприятия в малых и средних городах не могут своими силами решить проблему модернизации инженерной инфраструктуры, им необходима государственная помощь. Так, в Белогорске (Амурская область) после того, как муниципалитету были переданы коммунальные коммуникации
Министерства обороны и железной дороги, горсовету пришлось принимать специальную программу по их модернизации. По программе комплексного развития систем коммунальной инфраструктуры Белогорска на 2011-2020 гг. предусмотрено вложить 39 млрд. руб. На 75\% это средства федерального бюджета, на 20\% областного и на 5\% - местного [1]. Только так можно заменить обветшалые сети, которые не ремонтировались до этого десятилетиями.

Попытки привлечь деньги частных инвесторов (в рамках концессионных соглашений) в малых и средних городах, как правило, заканчивались неудачно. Исключением является Хабаровский край, где за время действия Федерального закона «О концессионных соглашениях» к 2017 г. на территории семи муниципальных районов заключено 44 договора о передаче концессионерам на условиях долгосрочной аренды 290 объектов коммунальной инфраструктуры [12]. Ряд соглашения был заключен в малых городах и поселках городского типа: в Амурске, Переясловке, Охотске. Чегдомыне. В других регионах ДФО ситуация намного хуже. Так, в Приморском крае в 2017 г. было заключено всего пять концессионных соглашений и только одно на территории малого города - Большой Камень.

Основными барьерами заключения концессионных соглашений в малых и средних городах ДФО являются: финансовое положение предприятий (высокие долги перед кредиторами), высокий износ основных фондов, требующих значительных инвестиций, а также отсутствие финансирования, достаточного для возврата инвестиций, в которых нуждаются системы коммунальной инфраструктуры.

Вышеприведенные примеры свидетельствуют, что в малых и средних городах модернизация инфраструктуры ЖКХ исключительно за счет потребителей и частных инвесторов неприемлема, нужна помощь из областного и федерального бюджетов. Здесь, безусловно, нужно анализировать экономическую ситуацию в каждом конкретном городе и помогать тем, кто находится в наиболее сложном положении.

Анализ хода реформы ЖКХ в малых и средних городах ДФО свидетельствует, что при ее разработке не была учтена специфика этих поселений, обусловленная, прежде всего, особенностями их территориального расположения, численностью потребителей ЖКУ, плотностью жилого фонда, небольшими объемами работ по 
управлению и обслуживанию жилья, а также неразвитостью рынка производителей ЖКУ. Не в полной мере учитывался низкий уровень доходов населения малых и средних городов, что не позволило за счет потребителей ЖКУ модернизировать сильно изношенную инженерную инфраструктуру. В результате влияния всех этих объективных факторов сложилась неблагоприятная ситуация, затрудняющая проведение реформы.

Стратегическим документом, определяющим основные направления реформы ЖКХ в ДФО, является «Комплексная программа модернизации и реформирования жилищно-коммунального хозяйства на 2010-2020 гг.», принятая распоряжением Правительства Российской Федерации 2 февраля 2010 г. Цель программы обеспечить к 2020 г. собственников жилых помещений всеми коммунальными услугами нормативного качества по доступной стоимости при надлежащей и эффективной работе коммунальной инфраструктуры. Успешная реализация Программы в малых и средних городах ДФО невозможна без достаточно серьезной государственной поддержки, прежде всего со стороны федерального бюджета. При этом надо учитывать специфику каждого города, подходить к выделению бюджетных средств индивидуально.

\section{СПИСОК ЛИТЕРАТУРЫ}

1. Аберр А. В ЖКХ Белогорска вложат миллиарды // Амурская правда. 2011. 23 сентября.

2. Александрова Т. Из барака в квартиру // Российская газета. 2014. 27 ноября.

3. Амурской области нужны частные инвестиции в ЖКХ // Издательство «Благовещенск. Дальний Восток» [Электронный ресурс]. - Режим доступа: http://www.blag-dv.ru

4. Бережная Ю. Отопительный сезон начнется в срок // Амурская правда. 2015. 28 августа.

5. В ДФО нужно обновление инженерных сетей // Информационный портал «ЖКХприм» [Электронный ресурс]. - Режим доступа: http:// gkhprim.ru/news

6. В Свободном семьи получают ключи от новых квартир в рамках программы по переселению из аварийного жилья // Портал «ЖКХ» [Электронный ресурс]. - Режим доступа: http:// www.zhkh.su/news

7. Данилов И. Свободненцы задолжали ЖКХ 50 миллионов // Амурская правда. 2004. 18 сентября.
8. Изношенность коммуникаций - основная проблема ЖКХ // Издательство «Благовещенск. Дальний Восток» [Электронный ресурс]. - Режим доступа: http://www.blag-dv.ru

9. Невинная И. Дорого и аварийно // Российская газета. 2007. 4 мая.

10. Население ЕАО должно за услуги ЖКХ более 750 млн. руб. // «Информационное агентство EAOmedia»[Электронный ресурс]. - Peжим доступа: http://eaomedia.ru/news

11. На обустройство бывших военных городков потребуется 2 млрд. руб. // Информационный портал «ЖКХприм» [Электронный ресурс]. - Режим доступа: http:/gkhprim.ru/news

12. О заключении концессий в сфере ЖКХ в Хабаровском крае // Официальный сайт Министерства ЖКХ Хабаровского края [Электронный ресурс]. - Режим доступа: http:/gkh27.ru

13. Регионы России. Основные характеристики субъектов Российской Федерации. 2017: стат. сб. М.: Росстат, 2017.

14. Регионы России. Социально-экономические показатели. 2002: стат. сб. М.: Росстат, 2002.

15. Регионы России. Социально-экономические показатели. 2009: стат. сб. М.: Росстат, 2009.

16. Регионы России. Социально-экономические показатели. 2015: стат. сб. М.: Росстат, 2015.

17. Регионы России. Социально-экономические показатели. 2017: стат. сб. М.: Росстат, 2017.

18. Российский статистический ежегодник. 2017: стат. сб. М.: Росстат, 2017.

\section{REFERENCES}

1. Aberr, A., 2011. V ZhKKh Belogorska vlozhat milliardy [Billions to be invested in housing and communal services of Belogorsk], Amurskya Pravda, September 23. (in Russ.)

2. Aleksandrova, T., 2014. Iz baraka v kvartiru [From the hut to the apartment], Rossiiskaya gazeta, November 27. (in Russ.)

3. Amurskoi oblasti nuzhny chastnye investitsii $\mathrm{v}$ ZhKKh [Amur Region needs private investment in housing and communal services]. URL: http:// www.blag-dv.ru (in Russ.)

4. Berezhnaya, Yu., 2015. Otopitelnyi sezon nachnetsya $v$ srok [The heating season will start on time], Amurskya Pravda, August 28. (in Russ.)

5. V DFO nuzhno obnovlenie inzhenernykh setei [Far Eastern Federal District needs renewal 
of engineering networks]. URL: http://www.zhkh. $\mathrm{su} /$ news (in Russ.)

6. V Svobodnom sem'i poluchat klyuchi ot novykh kvartir $\mathrm{v}$ ramkakh programmy po pereseleniyu iz avariinogo zhil'ya [Families of Svobodny will receive keys to their new apartments as a part of the program for relocation from emergency housing]. URL: http://gkhprim.ru/news (in Russ.)

7. Danilov, I., 2004. Svobodnentsy zadolzhali ZhKKh 50 millionov [Citizens of Svobodny owed 50 million rubles to housing and communal services], Amurskya Pravda, September 18. (in Russ.)

8. Iznoshennost' kommunikatsyi - osnovnaya problema ZhKKh [Infrastructure breakdown is the main problem of housing and communal services]. URL: http://www.blag-dv.ru (in Russ.)

9. Nevinnaya, I., 2007. Dorogo i avariino [Expensive and dangerous], Rossiiskaya gazeta, May 4. (in Russ.)

10. Naselenie EAO dolzhno za uslugi ZhKKh bolee $750 \mathrm{mln}$. rub. [Citizens of Jewish Autonomous Oblast owe more than 750 million rubles to housing and communal services]. URL: http://eaomedia.ru/news (in Russ.)

11. Na obustroistvo byvshikh voennykh gorodkov potrebuetsya $2 \mathrm{mlrd}$. rub. [2 billion rubles is required for the improvement of former military settlements]. URL: http://gkhprim.ru/news (in Russ.)
12. O zaklyuchenii kontsesii v sfere ZhKKh v Khabarovskom krae [On conclusion of concessions in the housing sector of Khabarovsk Territory]. URL: http://gkh27.ru (in Russ.)

13. Regiony Rossii. Osnovnye kharakteristiki sub'ektov Rossiiskoi Federatsii. 2017: stat. sb. [Regions of Russia. The main characteristics of the regions of the Russian Federation. 2017: statistical bulletin]. Moskva: Rosstat, 2017. (in Russ.)

14. Regiony Rossii. Sotsial'no-ekonomicheskie pokazateli. 2002: stat. sb. [Regions of Russia. Socio-economic indicators. 2002: statistical bulletin]. Moskva: Rosstat, 2002. (in Russ.)

15. Regiony Rossii. Sotsial'no-ekonomicheskie pokazateli. 2009: stat. sb. [Regions of Russia. Socio-economic indicators. 2009: statistical bulletin]. Moskva: Rosstat, 2009. (in Russ.)

16. Regiony Rossii. Sotsial'no-ekonomicheskie pokazateli. 2015: stat. sb. [Regions of Russia. Socio-economic indicators. 2015: statistical bulletin]. Moskva: Rosstat, 2015. (in Russ.)

17. Regiony Rossii. Sotsial'no-ekonomicheskie pokazateli. 2017: stat. sb. [Regions of Russia. Socio-economic indicators. 2017: statistical bulletin]. Moskva: Rosstat, 2017. (in Russ.)

18. Rossiiskii statisticheskii ezhegodnik. 2017: stat. sb. [Russian statistical yearbook. 2017]. Moskva: Rosstat, 2017. (in Russ.)

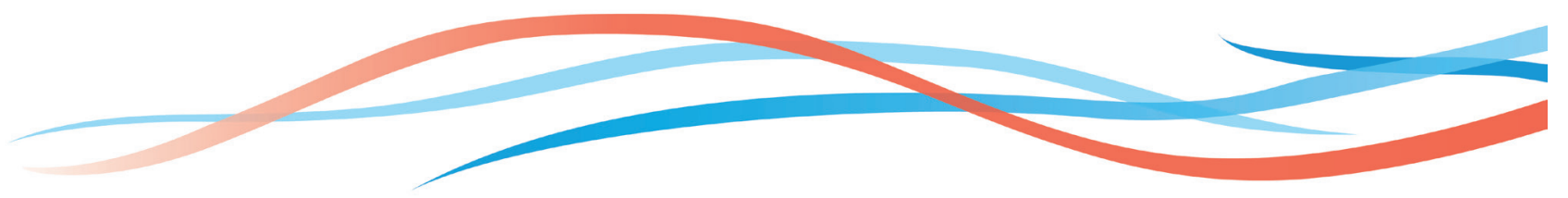

